\title{
Teacher Survey Response Analysis: the New Competencies-Based Computing Curriculum in General Basic Education Schools in Latvia
}

\author{
Viesturs VEZIS, Ojars KRUMINS \\ Faculty of Computing, University of Latvia, Raina bulv. 19, LV-1586, Riga, Latvia \\ viesturs.vezis@lu.lv, zm33068@lu.lv
}

\begin{abstract}
All general education schools in Latvia introduced comprehensive education system reform on September 1, 2020, including the introduction of a new subject "Computing" at all grade levels. The authors of this paper have been actively involved in the development of new subject since 2015, becoming involved in and chairing working groups to prepare methodological support for all computer classes from the $1^{\text {st }}$ to the $9^{\text {th }}$ grade (ages 7-16). This paper is based on a questionnaire of teachers from 150 schools who were involved in the pilot project to examine the new computing study programme. There is analysis and an evaluation of achievements, shortcomings, difficulties and possible challenges in introducing computer classes at all of Latvia's general basic education schools.
\end{abstract}

Keywords: didactics of computing, computer science, informatics, computing, curriculum, education, primary school, general basic education school.

\section{Introduction}

Active introduction of computing (computer science, information technology and/or informatics) classes have been occurring throughout the world for several years now (Storte et al., 2019). Sample computer study programmes were published in Latvia in 2015 for primary school students from the $1^{\text {st }}$ to the $9^{\text {th }}$ grade. These were prepared by a group of experts, including researchers from the Faculty of Computing at the University of Latvia, teachers, principals and representatives of professional computing associations (VISC, 2015).

A working group was set up to test and introduce these new programmes at Latvian schools. Its members included researchers from the Faculty of Computing at the University of Latvia, as well as computing teachers. The task of the group was to create methodological support for all computing lessons. This work continued from 2015 until 2018, and financial support was offered by companies from the computing industry. Methodological materials were prepared for 524 lessons. In parallel to this, the materials were tested at approximately 150 schools in Latvia (Studente, 2016; Start(it), 2018; Vēzis, 2019). All of the materials were posted on the Start(IT) portal (Start(it), 2018), which was used to provide educational support for students and teachers, as well as to conduct surveys among teachers about each of the classes that were taught. 
Each teacher who was involved in the testing had to fill out a questionnaire in which he or she evaluated the lesson that had been taught. This was done so as to ensure quick assurance of the methodological support for the classes and to also ensure that the classes were in line with the study programme. Teachers were asked to evaluate this in attitude scale and open question formats, indicating what was successful, what created difficulties, and what could be improved. The testing of the methodological materials lasted for three school years. At the end of each year, teachers were sent questionnaires and were asked to offer evaluations and comments about the educational materials and the programme as such.

In a previous paper (Vezis and Krumins, 2019) we discussed our experience in terms of why a new programme had to be established. We wrote about its origins, its testing and the main results. This paper, in turn, is devoted to an analysis of benefits, shortcomings, difficulties and opportunities as the new computing topic is introduced at primary education levels in Latvia. This will be based on an analysis of the open-ended questions that were in the survey questionnaires.

\section{Methods}

\subsection{Research design and participants}

The research was based on the questionnaire method (Fraenkel et al., 2011). It utilised closed questions (an attitude scale), as well as open-ended questions. The closed questions led to quantitative data, but they could not provide information about the true emotions of people, nor could they forecast successes, failures and their influence. Computing is a new topic in general basic education schools, and it is hard to forecast all of the possible situations which teachers encountered. The open-ended questions in the survey were meant to obtain as much information as possible about the introduction of this topic in schools. These are useful questions when studying a new topic (Sue and Ritter, 2012). In our case, this had to do with the introduction of a new and unprecedented subject at general basic education schools - computing.

Our survey covered all of the teachers who were involved in the testing. They were surveyed after each class that they taught and at the end of the school year. Teachers were also asked to compare and evaluate the quality of the educational process if the same topic was taught with future students after one or two years.

The research project began on September 1, 2015, and 154 pilot schools were involved in the testing of computing classes. Among these, 140 schools took part in all three years of the research (12 primary schools, 34 general basic education schools and 94 high schools and gymnasiums). This represented $19 \%$ of all schools in Latvia in the 2017/2018 school year (IZM, 2020). The pilot schools represented the full spectrum of Latvian schools in terms of size, type of school and location. It must be noted that the schools chose to test educational materials in various age groups, which is why there is a difference in the number of involved teachers and answers in each group of classes.

All of the data were obtained from the teachers who were involved in the aforementioned testing process at pilot schools. This means that the results can be extrapolated to the entire education system in Latvia. 


\subsection{Survey}

The questions in the survey were meant to learn the thoughts of teachers and to obtain precise information about what was successful, what created difficulties, and what and how things should be improved. The questions were about the study programme as such, as well as about each topic that was taught in each class.

Several focus groups were set up to prepare the questionnaires and the content and form of the relevant questions. These groups included computing teachers, leaders of methodological associations of informatics teachers, and deputy school principals who were responsible for informatics issues. The focus groups helped to make the questionnaire questions more precise and to test and improve them.

The following open-ended questions related to the study programme and environment:

- Do you think that there were one or more topics in the programme which students already were familiar with?

- What did you like the best about the Start(IT) learning environment and materials?

- What kinds of information were missing in the teacher part of the Start(IT) environment?

- What kinds of information were missing in the student part of the Start(IT) environment?

- How could the Start(IT) environment be improved?

- How could the computing study programme be improved?

- Do you have any recommendations for future work? If so, please write it down.

The following open-ended questions related to each topic in each class:

- If the content of the topic was inappropriate for the age group, then why?

- What difficulties did you encounter while teaching the topic?

- What would you change in teaching this topic?

During the second and third year, we also asked about teaching the same topic during the subsequent year:

- If you are repeating the topic, is it easier to prepare for lessons?

- If you are repeating the topic, is it easier to ensure the content of the lesson?

- If you are repeating the topic, is it easier to keep to the lesson plan minute by minute?

- If you answered 'more difficult this year' in any of the aforementioned questions, then why was that so?

- What did you do to ensure that lessons this year were better than last year?

- Which knowledge and skills did students remember from the previous year? What suggests that?

- Which knowledge and skills did students forget from the previous year? What could be done to improve this knowledge and skills?

Questionnaires about each lesson included the following questions:

- Evaluate how targeted and result-focused was the proposed learning process during the lesson?

- Evaluate how did you do manage to fulfil everything that was planned during the lesson? 
- To what extent did the teaching methods motivate students to do the work?

- To what extent were the teaching methods, form of organizing the work and associated materials in line with the achievable result during the lesson?

- How could the lesson be improved?

Google Forms were used to collect data, and Microsoft Excel data processing, analysis and visualisation tools were used to process and analyse the data.

Because of the specifics of the research question and questionnaire, data processing involved both quantitative and qualitative methods. Quantitative methods were used to process the questions which had numerical answers (attidude scales), as well as the ones which involved a multiple-choice list of answers. Open-ended questions, for their part, were primarily analysed with qualitative methods, making use of context analysis and text coding (Creswell and Poth, 2016).

\section{The results of computing testing at the end of each learning period}

\subsection{The results of the testing at the $\mathbf{1}^{\text {st }}$ grade}

We received questionnaires from 123 teachers from 102 pilot schools. Slightly more than one-half $(60 \%)$ did not indicate any difficulties in the teaching process. Those teachers who did indicate difficulties, for their part, mentioned these:

- Many materials have to be printed out and given to the students

- Students are very different

- Students lack patience and are careless

- Entering of a username and password

- Terminology

- Students do not see algorithms in real life

- Theory is boring

- There are differences between writing characters on various types of devices, particularly when it comes to the specific Latvian language with its diacritical markings

- Students are not familiar with a keyboard

- Text processing and web usage topics are hindered by the poor writing and reading abilities of students

- Students have varying levels of pre-skills, and there are things such as using the web which students already know how to do

- Students are surprised that the Internet is not only used to play games

Asked what they would change in the process, $91 \%$ of respondents said nothing. Those who proposed changes made these recommendations in terms of improving methodological support for the teaching process:

- Give more time to learn the subject

- The first topic (about algorithms) should be taught immediately at computers and not with pen and pencil

- Teach the school management system (electronic diary) during the first semester

- Use a full-fledged text editor to process text

- Offer other websites during lessons 


\subsection{The results of the testing at the $2^{\text {nd }}$ grade}

We received questionnaires from 120 teachers from 99 pilot schools. A bit more than one-half $(54 \%)$ reported no difficulties in the process, while those who did report difficulties mentioned these issues:

- Students have a very different rate of work

- Terminology in Latvian is a big problem, and at schools, at least, we must try to use the correct terms (https://termini.gov.lv/)

- Sadly, most webpages have too much text for a $2^{\text {nd }}$ grade student

- Schools do not have devices such as cameras to attach to the computer; sometimes it is hard for students to attach these devices to computers

- Work with multiple graphical user interface windows

- Work with text if the student has poor native language skills

- Algorithms - a lack of a strategy for seeking out errors

- The skill to work independently; some students lacking patience

- Maintaining attention; students do not pay attention

- Reading skills

- Students forget their passwords

- Parents do not want their children to use the Internet, including the learning environment and the school management system (electronic diary).

The vast majority of teachers said that they would not change anything in the process. There were no notable recommendations on improving methodological support for the process.

\subsection{The results of the testing at the $3^{\text {rd }}$ grade}

We received questionnaires from 108 teachers from 93 pilot schools. Slightly more than one-half $(54 \%)$ of respondents reported no difficulties in the process, while those who did speak to problems mentioned these:

- Students find it hard to use terms and concepts

- Students lack motivation to learn

- Students do not want to think in-depth about a topic

- Students lack the patience to complete the assignment

- Some students work slowly

- Students do not like theory

- Students are afraid to make mistakes

- Students are convinced that they already know everything

- Students who are poor at maths also do poorly at computing

- There are technical problems such as a lack of necessary devices or a slow Internet connection

93\% of respondents made no recommendations about improvements, while those who did made these:

- Different teachers would shorten or extend the amount of time that is devoted to each topic

- Use of robots

- More assignments for practice 


\subsection{The results of the testing at the $4^{\text {th }}$ grade}

Because the testing began simultaneously at the $1^{\text {st }}, 4^{\text {th }}$ and $7^{\text {th }}$ grade level, students who studied computing at the $4^{\text {th }}$ grade had not learned it before. That meant that it was a new topic for them. We received questionnaires from 123 teachers from 102 pilot schools. $70 \%$ said that there were no problems, while those who did indicate problems mentioned these:

- Some of the terminology was too complex

- Students had different levels of experience and skills

- There was a lack of devices for photography lessons

- Students had problems in using multiple applications during a single lesson

- Not everyone could save data in the cloud

- Students type text very slowly

- Concepts such as social engineering, intellectual property, IP address and URL are too complicated

- Students forget usernames and passwords

- Creating an E-mail account

- Some teachers did not manage to teach the topic of algorithmics (they spent more on previous topics)

Asked what they would change in the process, $89 \%$ said nothing, but those who proposed changes made the following suggestions:

- Different teachers would shorten or extend the amount of time that is devoted to each topic

- Teach topic about image processing in another grade

- Teach the use of Internet services at the beginning of the school year

\subsection{The results of the testing at the $5^{\text {th }}$ grade}

We received questionnaires from 95 teachers from 87 pilot schools. $63 \%$ said there were no problems. Those who said that there were problems mentioned these:

- Difficulties in assessing the reliability of information

- Students forgetting passwords and "secret questions" to restore them at the beginning of the year

- Students cannot identify the main aspects of information that they have acquired

- Students do not understand cloud services and have problems with online co-operation

- Students have difficulties in preparing algorithms and preparing flowcharts

- Students have problems with coding and debugging

- Teachers have difficulties in finding mistakes in source code made by students so as to help to address them

- Recognition of loops in given assignments (algorithms)

- A lack of patience

- Students do not want to work with paper and pencils during a computing lesson (they only want to work with the computer)

- Students quickly got tired of working with Scratch (https://scratch.mit.edu/)

- Difficulties in remembering the units of information (byte, $\mathrm{kB}, \mathrm{MB}$, etc)

- Different work tempos, particularly in terms of assignments related to algorithms

$94 \%$ of respondents would not change anything in the topic, and there were no substantial recommendations from the others. 


\subsection{The results of the testing at the $6^{\text {th }}$ grade}

We received questionnaires from 80 teachers from 73 pilot schools. $45 \%$ said that there were no problems, while the others mentioned these difficulties:

- The motivation and ability of students to finish work that they started

- The belief of students that they already know everything about the subject

- No desire among students to take an in-depth look at issues

- Different work tempos among students

- Students do not want to plan algorithms, "the poking method," "no algorithmic thinking"

- Organising group work

- Difficult topics:

$\circ$ Archiving

- Synchronisation of data

- The relative and absolute addressing of cells in spreadsheets, use of mathematics

- Types of graphics (vector/raster)

- Header and footer, footnotes, multilevel numbering and bulleting, long texts, "Paste Special"

- Flowcharts

$85 \%$ of respondents said that no changes were needed in the process, while others made the following recommendations:

- Devote more or less time to a topic

- Offer more assignments to capable and weaker students

- Teach in a higher or lower grade

- Attend teacher courses

- Some teachers said that students loved the topic "Drawing, Animation and Image Processing"

\subsection{The results of the testing at the $7^{\text {th }}$ grade}

Students who took this topic at the $7^{\text {th }}$ grade level had also taken it at $5^{\text {th }}$ and $6^{\text {th }}$ grade, so these students already had some experience with computing lessons. Questionnaires were received from 123 teachers from 102 pilot schools. 63\% said there were no problems, while others mentioned the following issues:

- Encouraging students to evaluate and analyse information

- Students with no interest

- Theory presented in a boring way

- Too many assignments for each lesson

- Difficulties with subtopics such as cloud storage and flowcharts

- Excessively childish work for $7^{\text {th }}$ grade students

- The topic of algorithms is exhausting

- Students do not like theoretical lessons

- Students with a lack of initial knowledge find it hard to learn about algorithms and software design 
$88 \%$ of respondents said that they would change nothing, while others proposed:

- More diverse assignments

- Use of a project method

- Use of robots

\subsection{The results of the testing at the $8^{\text {th }}$ grade}

Questionnaires were received from 58 students from 49 pilot schools. 68\% said there were no problems, while others mentioned these:

- Security - lack of the motivation among students who thing they knew enough about it

- $\quad$ Seeing and writing down algorithms

- Debugging

- Poor attention and a lack of patience

- The configuration of computers makes it impossible to change a few things in the operating system that should have been learned (e.g., power settings)

- Different apps at school and at home, and different app interface languages at school and at home

- A lack of equipment for filming and video editing (cameras, headphones)

- Respect for copyright requirements

- Insufficient mathematical knowledge for algorithmic topics

- Reading literacy with understanding

$94 \%$ of respondents said that they would not change anything, and no one had significant suggestions.

\subsection{The results of the testing at the $9^{\text {th }}$ grade}

We received questionnaires from 45 teachers from 42 pilot schools. 54\% mentioned no problems, while others mentioned these:

- Students do not want to learn theory

- Students think that they know everything

- Students wonder why they need to learn these things

- Students do not know how to do independent work

- Topics which created difficulties:

$$
\begin{array}{cl}
\circ & \text { Arrays } \\
\circ & \text { Work with large documents } \\
\circ & \text { IF, AND, OR functions } \\
\circ & \text { No skills in using mathematics } \\
\circ & \text { Data import/export rules }
\end{array}
$$

$89 \%$ said that they would not change anything in the process, while others mentioned such recommendations:

- Add more examples from everyday life

- More independent work assignments

- Automatized tests

- Teaching some topics at the high school level 


\subsection{Start(IT) environment and support materials}

202 responses were received to the open-ended question "What did you like the best about the Start(IT) learning environment and materials?" Those mentioned most often are seen in Figure 1.

Exercises and assignments

Presentations

Lesson plans

Everything needed for the lesson

Available choices

Transparency, logic, structure

Diversity

A corner of useful things

A corner of useful things

Assignments linked to real life

Answers to assignments

Interesting assignments

Students have to study on their own

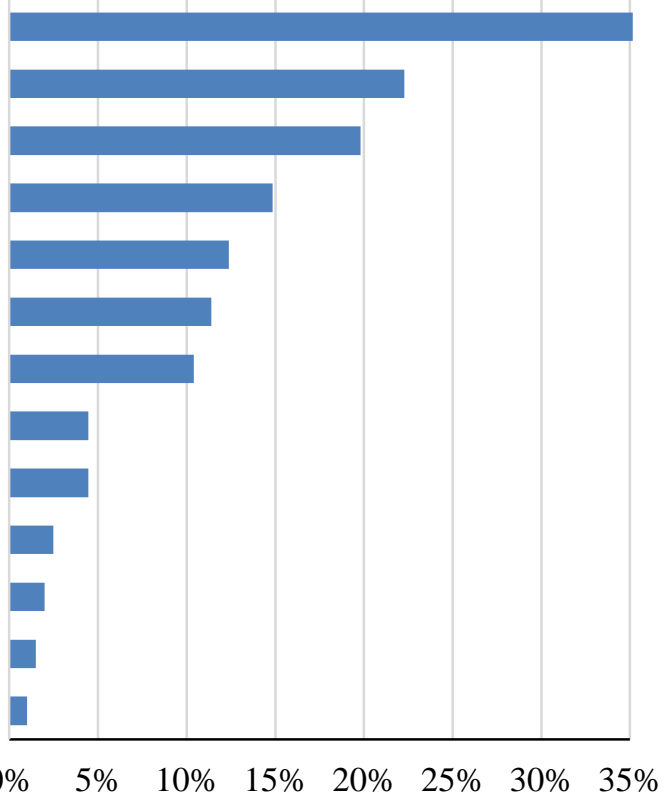

Fig. 1. Things which teachers liked about the Start(IT) environment and materials

The teachers also wrote down commentary, and as far as these authors are concerned, these were the most often mentioned and the most important ones:

- The fact that there are materials for each lesson and descriptions of methodology

- Appropriateness of materials for age groups

- The ability to choose assignments based on student preparedness

- Chronological sequence and materials

- A logical lesson plan with appropriate exercises and independent work

- The environment is transparent and easy to use

- Transparency, gradualness, visual design, links between assignments and real Start(IT) environment and support materials

\subsection{Shortcomings in the teacher part of the Start(IT) environment}

202 teachers answered the open-ended question "What kinds of information were missing in the teacher part of the Start(IT) environment?" 93\% said that everything was fine and left no comments, but just a few teachers wanted the teacher section to be expanded. The issues mentioned most often are seen in Figure 2. 
A place to add new tasks

More theory

More assignments

Hard to make my way through titles

Downloading all files as ZIP archive

Solutions of tasks

Automated checking of student answers

Calendar of future events

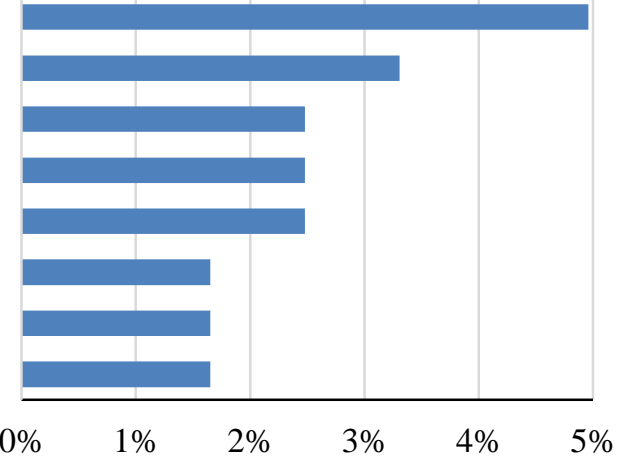

Fig. 2. Information missing from the teacher part of the Start(IT) environment (\% of answers)

Teachers were asked to make comments about what was missing in the Start(IT) teacher part. As far as the authors are concerned, these are the most frequently mentioned and important of them:

- Additional assignments for students who completed given tasks

- More in-depth materials

- Video lectures

- Handouts

- Explanations of IT terms

- Reminders and evaluation columns

- The most frequent coding errors

- Links to resources are outdated

- The ability to communicate with colleagues (forum)

\subsection{Shortcomings in the $\operatorname{Start}(\mathrm{IT})$ student part}

202 teachers answered the open-ended question "What kinds of information were missing in the student part of the Start(IT) environment?", focusing on the student section. $89 \%$ of teachers said that everything was fine and did not leave any comments. Only some teachers wanted supplementations to the student section, and the most commonly mentioned issues are seen in Figure 3.

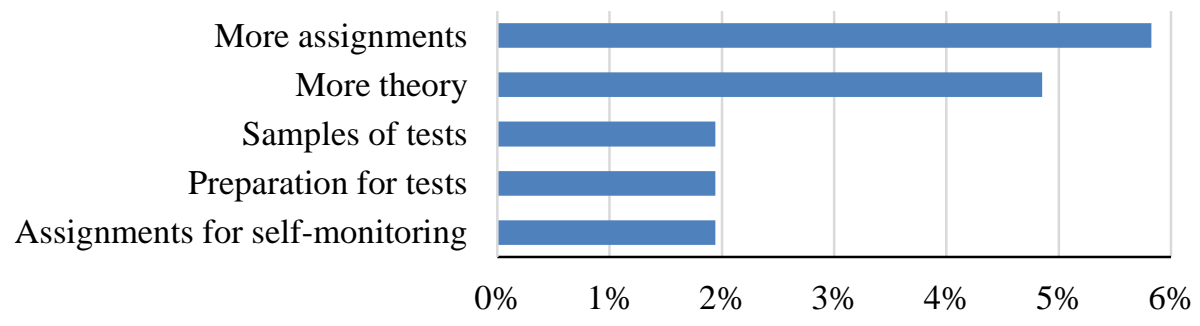

Fig. 3. Information that is lacking in the student part of the Start(IT) environment (\% of answers) 
As far as the authors are concerned, the most often mentioned and significant comments about what is lacking in the student part were:

- Assignments for self-monitoring

- More of updating (warm-up, engage). Perhaps there should be recommendations at the beginning of how to motivate students to learn the topic.

- Publish updates, as well as competitions about various IT-related projects

- Example solutions of the tasks so that students can do the job themselves

- Scratch exercises could have brief explanations because students have different questions or issues. Maybe there could be a sprite which tells the commands to choose. Because of different problems, the frontal work with the entire class is difficult.

- Links for additional learning

- $\quad$ Some links did not work

\subsection{Recommendations from teachers on how to improve the Start(IT) environment}

Teachers were asked about ways in which to improve the teaching environment. 107 answers were received from 202 teachers, and most of them said that everything was fine. Here are suggestions from other teachers:

- Prepare materials in Latvian and do not offer to use games in English

- Topics should be arranged differently

- It is hard to use the system, particularly in $1^{\text {st }}$ grade, because a lot of time is spent on entering a user name and password; couldn't there be free (without login) access to materials?

- Improving contacts between teachers and students, including chat opportunities

- $\quad$ Automated tests and grading

- Interactive materials, video lectures

- Ability to transfer grades to the school management system (electronic diary)

- Create materials online, for instance, Online Office

\subsection{Proposals from teachers on improving the computing study programmes}

95 teachers of 202 answered the open-ended question "How could the computing study programme be improved?" Only a few teachers proposed improvements to the programme, and the main ideas are in Figure 4. 
Less content, too difficult Coordinate with new standart More time to shore up skills More structured topics, too fragmented More lessons about the Internet Fix mistakes, update information

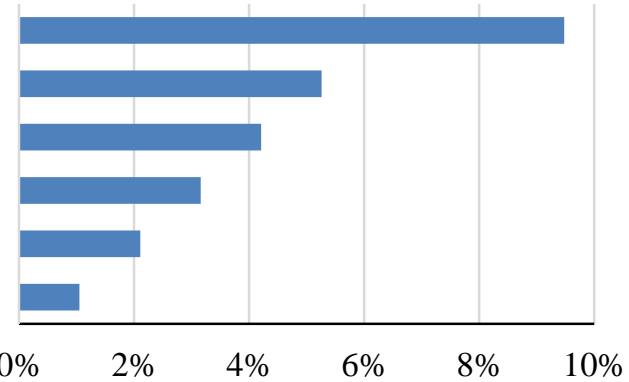

Fig. 4. Recommendations to improve the study programmes ( $\%$ of answers)

The authors feel that these were the most often mentioned and important comments on how the programmes could be improved:

- Lessons not just for the transfer phase study programme, but also the standard study programme that will be implemented after the transfer phase

- More links to other topics

- Just one new topic per lesson

- Feedback of the previous lesson

- More time for some topics

- Increase number of lessons

- We could not complete one lesson in 40 minutes

- Courses and seminars for teachers, evaluating them together

- Interactive assignments at the end of the school year

- Sometimes the number of materials to be studied is too large, sometimes too small

- More exercises

- Less theory, more practical work

- Integration of more assignment texts in the assignment file, less paper

- More interesting assignments for students

- Teach also other apps, operating systems and programming environments

\section{Discussion}

The second chapter correlates proposals and difficulties which teachers mentioned in their questionnaire. Most teachers did not indicate any problems in teaching computing topics. The things written in the questionnaires can be used to improve the study programme and to come up with new educational materials.

\section{Reliability of data}

The reliability of the results about the testing of the new educational content in computing is ensured by the fact that the data were received from all of the teachers who were involved in the testing process. The authors have no reason to think that any of the respondents provided formal or false answers to the questions. It has to be noted that for reasons independent of the teachers, not all of the lessons that were scheduled for the school year were taught, and sometimes a few planned lessons to shore up and/or repeat 
information were missed. The result was that student results might be poorer than would be the case if all of the lessons had been taught. Another factor that might influence the quality of the education process is the pre-prepared readiness of the teachers who were involved in the testing when it came to the content. This was seen in things which some teachers said about the first year when they teach the topic and the repeated teaching of the same topic one or two years later.

\section{Opposing views}

Teachers often proposed opposing recommendations. One teacher wrote that there was too much material and not everything could be handled during one lesson, while another teacher of the same lesson said that additional assignments were needed. A great variety of assignments would allow teachers to choose which ones to use, as well as to differentiate work with each student and to choose various assignments for each student. It is evident that teachers who used the materials for the first time did not yet have experience to choose which assignments were most effective for specific students. When teaching the same content to the next class of students, the teachers said that it was easier to select sets of assignments for each lesson, as well as to differentiate the content in terms of each student's abilities and level of preparation.

\section{Use of terminology}

There were distinct difficulties with terminology and concepts among younger students. Before a $1^{\text {st }}$ grade student could start to work with a computer, he needed to login sign into the system with a user name and password, these to be entered with a keyboard and a mouse. Students needed to use the mouse cursor, the screen buttons, the menu, the icon, the click, the double-click and the window. As could be seen in the previous sentence, even the simplest work with a computer means the necessity to be familiar with lots of terminology. It is understandable that there are many new words for the youngest students to remember. The study programme shows that students in the first three grades encountered at least 85 different computer-related terms. In most cases, students are not asked to define the terms. As authors, we asked the teachers to use the correct terms so that students could hear and see them. Everyday use of terms means that students can gradually learn them.

Another problem is that terms that are used in conversational Latvian are often borrowed from other languages or are simply wrong (Borzovs et al., 2013; Kokareviča, 2017). A comparable situation is found in other countries where English terms are seen as undesirable (Marković and Rajović, 2016; Vidović and Mezak, 2017; Karfis, 2020).

\section{Motivation}

Quite often and particularly in relation to the $3^{\text {rd }}$ and $6^{\text {th }}$ grade, teachers said that students lacked motivation to learn. Research and interviews of teachers showed that this was a problem not just in computing, but also in other subject areas. In the $1^{\text {st }}$ grade, the student is in a new and interesting environment, but further along, the interest tends to dissipate, and teachers must use new methods to keep the interest of the students (Dancite, 2017). Students often see a computer as nothing other than a source of entertainment. This is seen in the surveys and in results from other researchers (Oliemat et al., 2018). Student motivation, particularly at the primary school level, was often enhanced by using games, particularly when teaching algorithmic assignments (Hainey et al., 2016; Andic, 2018; Barradas, 2020). Other studies argue the opposite - in lower 
grades, there must be caution about the types of games that are given to students (Lambić et al., 2020).

Teachers also said that some students have confidence that they already know everything. Or at least "everything they need". This, too, reduces the motivation of students to learn something new. Some students really do know a lot about the things that are of interest to them. They are familiar with various communication or entertainment apps on their smartphones, but they lack the knowledge and skills to process information or produce their own content (Smahel et al., 2020).

The use of various devices and the speed of life (Santarius and Bergener, 2020) mean that students today do not want to take an in-depth look at assignments and lack patience. Students day-to-day encounter brief and simple assignments that do not require an in-depth look and that means that they do not develop the ability to complete complicated tasks. That was seen in our research, as well.

It may be that the patience of students or their refusal to complete assignments are influenced by the number of assignments that they have completed successfully. This is also pointed out by other authors whose studies showed that students aged 7 or 8 were capable of completing fewer assignments than students who were 9 or 10 . Their attitude toward software design, too, was not as positive as was the case with slightly older students (Lambic, 2020).

Primary school teachers said that the children are afraid of making mistakes, even though learning from one's own mistakes and those of others is one of the most important ways of learning new things (Metcalfe, 2017). Algorithms aimed at dealing with problems very often and normally involve mistakes. This is something that would require separate study to find out whether the problem has to do with computing materials, teaching methods, or issues that exist in all subject areas.

Some teachers say that students often say that they know a lot or everything about the topic at hand. Conversations with teachers and personal experience show that students at best have generalised knowledge about the computing topics that are taught. Sadly, this attitude leads to carelessness, and that leads to poor results in tests.

\section{Technical problems}

Quite a few teachers pointed to technical problems such as a lack of sufficiently powerful and fast computers at schools. Work is hindered by a lack of mobile devices, video cameras, headphones and other equipment. The last time that new computers were delivered to schools at the national level was in 2012, when the school informatization project was completed (RD IKSD, 2012). Since then, many local governments have bought new computers for its schools, but only to the extent that it can afford to do so. The local government in Riga has purchased new computers several times, so the situation in the capital city is comparatively good. Other local governments have a harder time in finding the necessary resources.

\section{The Start(IT) environment}

Answers from teachers suggest that they enjoyed the Start(IT) environment. Teachers were most happy about exercises, assignments and lesson plans which help to prepare for classes in a simpler way. Each lesson has lots of exercises and assignments, so a teacher must only select those assignments which should be given to the students. Teachers also appreciate the fact that the educational materials are easy to review and are structured. One problem is that only a few teachers said that they enjoy the linkage between assignments and real life. This is a topic that requires further study. Perhaps it is 
not sufficiently accented in educational and methodological materials, and so it has not occurred to teachers. Several teachers note that there are not enough materials for warmup and engaging, which is somehow related to linkage with real life.

A majority of teachers did not leave comments or claimed that everything is fine about the Start(IT) environment. This suggest that we have established educational materials and an environment that are appropriate for most teachers and students. A comparison to methodological materials in other school subjects show that they usually have sequence in the learning of the topic and a few examples of assignments, but there are not lesson plans and assignments for each lesson, to say nothing of a full methodological support for each lesson in the plan.

Some teachers said that it should be possible to download all materials for a lesson in the ZIP archive format, but that was done purposefully so that teachers would use the educational environment to a greater degree.

Several teachers asked for video lectures which could be shown to students, but the authors of the methodology feel that it is better to demonstrate activities with a computer in real life, as opposed to showing a video lecture to students. It is also true that computer software is constantly improved and changed, which means that video materials quickly become out of date. High-quality video lectures are also much more expensive in terms of the return on the investment.

There are teachers who wish for publication of IT news in the student part of the Start(IT) environment, but that is work that would require regular human resources and financing. Authors have no such resources, and there is no support for it at the national level. At the moment partially this is done by Start(IT) Facebook web page (WEB, a).

A key shortcoming is that teaching materials should have references to external sources with hyperlinks. Hyperlinks, too, often are out of date because the content of the source has been erased or changed. This requires ongoing work to update materials or at least links. This, too, requires regular human and financial resource, but the government and the industry have proven unwilling to pay for such work. This problem could be addressed if teachers themselves could improve or supplement teaching materials, but in that case there would have to be a salaried monitor who tracks the changes and makes sure that they are appropriate.

\section{Computing at the $\mathbf{1}^{\text {st }}$ grade}

When we put together methodological materials to make sure that $1^{\text {st }}$-grade students found it easier to adapt to life at school, we proposed that the first lessons be taught in a regular classroom and not a computer lab. Introductory assignments aimed at developing logical thinking via games were meant to be handled on paper. Several teachers, however, said that the children immediately wanted to sit down at the computer and work with it. We wish to point out that when children start school, that means that throughout their education they must establish, strengthen and improve secure usage skills for computers and smart devices so as not to harm themselves or others. Before using a computer, particularly one that is in common use, students must learn a few simple rules on working safely with computers and smart equipment. These rules are age-appropriate, because security is the issue about which not just $1^{\text {st }}$-grade children, but the public at large have the least understanding.

Teachers said that at first they had thought that algorithms would be the hardest topic in the $1^{\text {st }}$ grade, but it turned out that the children did best in this specific area. The same was said by many $2^{\text {nd }}$-grade teachers - topics related to algorithms were very successful. 
Some teachers said that students were unfamiliar with keyboards, which complicated work with a computer. These authors believe that this is good, because that means that children can be taught to use a keyboard in an effective manner. Nothing is harder than changing skills and habits that are incorrect and have been learned in the past. Keyboard skills must be shored up at all computing classes, particularly focusing on the need for students to hold their arms appropriately and to write texts on the computer with all ten fingers.

Many teachers said that students found it hard to sign into the system or took a long time in doing so. This must be simplified as much as possible in terms of using comparatively simple usernames and passwords while, at the same time, encouraging at least minimal understandings about safe passwords. Perhaps there must be a search for different ways to guarantee safe authentication for school computers - biometry, for instance.

When we were putting together the materials, one problem was that it is hard to find websites that are appropriate for the $1^{\text {st }}$ grade students. Most websites have too much content that is not appropriate for this age group. The size of letters is not appropriate and the choices are complicated. We asked teachers to share their knowledge of appropriate websites that they themselves found, but teachers proposed very few of them to us. The conclusion must be that there is an open niche for website designers who could offer content for children at lower grade levels, including those who have poor reading skills.

Despite these problems, the research shows that the methodological support for the educational process at the $1^{\text {st }}$ grade level is supportive and can be used successfully.

\section{Computing from $2^{\text {nd }}$ to $9^{\text {th }}$ grade}

Teachers suggested that some topics should be taught in different classes, because the topics would be necessary in other subject areas or because the topic was unfamiliar to students. Teachers, for instance, suggested that digital imagery be taught later, but that is not advisable, because this is a skill which other subject teachers demand from their students quite early in the educational process. That means that it is valuable to first teach some topics in the computing class so that they can be used for other lessons, as well.

All of the questionnaires suggested that students don't like to learn theory. Much thought must be given on how to change the educational methodology and approaches so as to ensure that learning the necessary theoretical issues would be more interesting for students. The materials from these authors have not always been successful in this regard, but the authors do not believe that the whole educational material must always be "interesting" or "playful." There are things which students must simply know or be able to do to enter society and use computers in an effective and secure way.

\section{Conclusion}

The testing results show that computing can be taught successfully as a separate topic and starting at the $1^{\text {st }}$ grade level. One problem for primary school students is signing into computers. The industry should work on solutions that would help younger students to sign in without compromising security. Another problem is that there are not enough web resources in Latvian that are appropriate for primary school students. 
The authors wish to argue that the nihilistic attitude toward the use of proper and appropriate terminology in computing and other subject areas, as well as the public at large, must be put to an end at the national level. This applies to state-issued normative documents and recommended methodological and educational resources. Work must continue on improving the programmes for computing and other study areas, harmonising these so that students have a better sense of how computing can be used in other subject areas. There must be resources to regularly update and improve the methodological support that is in the Start(IT) environment and resources to regularly update computers which are available at schools.

The survey results show that the educational programme and the teaching materials are optimal and in line with the age of students. Most teachers said that the materials were appropriate and saw no reason to change them. Only some teachers spoke of difficulties in teaching the content. Some of these difficulties had nothing to do with computing subject, but instead with education as such (classroom work in all subject areas). Most of the difficulties can be overcome if each teacher improves experience in teaching the new subject of computing.

The conclusion for the authors is that the sample educational programmes and the methodological support for the process in each classroom lesson could be introduced in all general education institutions and from the $1^{\text {st }}$ to the $9^{\text {th }}$ grade. We also wish to say that the methodological support that was established by a group that was led by authors has been taken as a foundation for the Latvian Cabinet of Ministers Regulation No. 747, "Regulations on sample state basic education standards and basic education programmes" insofar as this regulation has to do with computing issues (Ministru Kabinets, 2018). The rules have been introduced at all of the relevant educational institutions as of September 1, 2020.

\section{References}

Andic, B., Kadic, S., Grujicic, R., Malidžan, D. (2018) A Comparative Analysis of the Attitudes of Primary School Students and Teachers Regarding the Use of Games in Teaching. IAFOR Journal of Education, 6(2), 5-16.

Barradas, R., Lencastre, J. A., Soares, S., Valente, A. (2020). Developing computational thinking in early ages: a review of the code. org Platform.

Borzovs, J., Ilziņa, I. I., Keiša, I., Pinnis, M., Vasiljjevs, A. (2013). Usage habits of information technology terms in public communication (in Latvian) http://dspace.Iu.IV/dspace/bitstream/handle/7/1419/ Borzovs et al Terminu paradumi.pdf

Creswell, J. W., Poth, C. $\bar{N}$. (2016). Qualitative inquiry and research design: Choosing among five approaches. Sage publications.

Dancīte, A. (2017) Teacher's activities in promoting learning motivation in primary school (in Latvian). https://dspace.Iu.Iv/dspace/handle/7/37493

Fraenkel, J. R., Wallen N. E., Hyun H. H. (2015). How to design and evaluate research in education. New York: McGraw-Hill Education.

Hainey, T., Connolly, T. M., Boyle, E. A., Wilson, A., Razak, A. (2016). A systematic literature review of games-based learning empirical evidence in primary education. Computers \& Education, 102, 202-223.

IZM (2020). Izglìtības un zinātnes ministrija. Ministry of Education and Science Official statistics on general education, 2017-2018 school year. https://www.izm.gov.IV/IV/20172018-macibu-gads

Karfis, O. (2020). French Computer Terms. French Today. https://www. frenchtoday. com/blog/french-vocabulary/learn-some-french-computer-terms/ 
Kokareviča, D. (2017). "Shortcut", "screenshot" and other strange language animals, https://www.Ia.Iv/sortkats-ekransavins-un-citi-jocigievalodas-zveri

Lambić, D., Đorić, B., Ivakić, S. (2020). Investigating the effect of the use of code.org on younger elementary school students' attitudes towards programming. Behaviour \& Information Technology, 1-12.

Marković, N., Rajović, J. (2016). Influence of English language on Serbian language in the context of computer terminology. Technics and Informatics in Education $6^{\text {th }}$ International Conference.http://www.ftn.kg.ac.rs/konferencije/tio2016/Radovi $\% 20$ TIO202016/EN/3) 20Information:20and\%20Educational\%20Technolog ies/315 017 Markovic Rajovic EN.pdf

Metcalfe, J. (2017). Learning from errors. Annuă review of psychology, 68, 465-489.

Ministru Kabinets (2018). Cabinet of Ministers Regulation No. 747, 27 November 2018. Regulations on sample state basic education standards and basic education programmes (in Latvian), Latvijas Vēstnesis, 249

Nogry, S., Varly, P. (2017) Everyday Laptop Use by Children in a Southern Country: A MixedMethodApproach. Journal of Research on Technology in Education, International Society for Technology in Education, 1-16.

Oliemat, E., Ihmeideh, F., Alkhawaldeh, M. (2018). The use of touch-screen tablets in early childhood: Children's knowledge, skills, and attitudes towards tablet technology. Children and Youth Services Review, 88, 591-597.

RD IKSD (2012). Completed ERDF project "Informatisation of general education schools in Riga" (in Latvian). http://old.iksd.riga.lv/public/49094.html

Santarius, T., Bergener, J. (2020). Does the Use of ICT speed up the Pace of Life? In Proceedings of the 7th International Conference on ICT for Sustainability, 107-115.

Smahel, D., Machackova, H., Mascheroni, G., Dedkova, L., Staksrud, E., Ólafsson, K., Livingstone, S., Hasebrink, U. (2020). EU Kids Online Survey results from 19 countries. https://doi.org/10.21953/Ise.47fdeqj01ofo.

Start(it) (2018). IT Education Foundation. Start(IT) Computing (in Latvian) https://datorika.startit.Iv/

Storte, D., Webb, M., Bottino, R.M., Passey, D., Kalas, I., Bescherer, C., Smith, J. M., Angeli, C., Katz, Y., Micheuz, P., Rosvik, S. (2019). Coding, Programming and the Changing Curriculum for Computing in Schools.

Studente, L. (2016) .Computing study pilot project: what conclusions after the first year? (in Latvian) VSIA "Latvijas Vēstnesis". https://Ivportals.lv/norises/281595datorikas-pilotprojekts-kadi-secinajumi-pec-pirma-gada-2016

Sue, V. M., Ritter L. A. (2012). Conducting online surveys. Sage.

Vēzis, V. (2019). Computer seriously finds its place in the educational content of the school what has been done and what follows (in Latvian). https://www. Ips. Iv/uploads/ docs module/201906 06_Datorika_LPS20190606.pdf

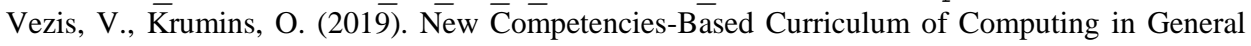
Basic Education Schools in Latvia and its Testing. Baltic Journal of Modern Computing, 7(3), 364-379.

Vidović, E., Mezak, J. (2017). University Students' Attitudes Towards the Use of Anglicisms in ICT-Implications for Policy And Practice. In: Contributions to the development of the contemporary paradigm of the institutional childhood: An educational perspective. Lit Verlag GmbH \& Co. KG Wien.

VISC (2015). National Centre for Education. Existing samples programmes in primary education (in Latvian) https://visc.gov.lv/vispizglitiba/saturs/programmas_ pam izgl old.shtml

WEB (a). Start IT Facebook page. https://www. facebook. com/startit IV

Received May 22, 2021, revised June 23, 2021, accepted June 24, 2021 